\title{
Silicone Nanofilament-Supported Mixed Nickel-Metal Oxides for Alkaline Water Electrolysis
}

\section{Journal Article}

\section{Author(s):}

Abbott, Daniel F.; Meier, Margrith; Meseck, Georg R.; Fabbri, Emiliana; Seeger, Stefan; Schmidt, Thomas J.

Publication date:

2017-01

Permanent link:

https://doi.org/10.3929/ethz-b-000191286

\section{Rights / license:}

Creative Commons Attribution 4.0 International

\section{Originally published in:}

Journal of the Electrochemical Society 164(4), https://doi.org/10.1149/2.0201704jes 


\title{
Silicone Nanofilament-Supported Mixed Nickel-Metal Oxides for Alkaline Water Electrolysis
}

\author{
Daniel F. Abbott, ${ }^{\mathrm{a},=, *}$ Margrith Meier, ${ }^{\mathrm{b},=}$ Georg R. Meseck, ${ }^{\mathrm{b}}$ Emiliana Fabbri, ${ }^{\mathrm{a}}$ \\ Stefan Seeger, ${ }^{\mathrm{b}, \mathrm{z}}$ and Thomas J. Schmidt ${ }^{\mathrm{a}, \mathrm{c}, *, \mathrm{z}}$
}

\author{
${ }^{a}$ Electrochemistry Laboratory, Paul Scherrer Institut, CH-5232 Villigen, Switzerland \\ ${ }^{b}$ Department of Chemistry, University of Zürich, $\mathrm{CH}-8057$ Zürich, Switzerland \\ ${ }^{c}$ Laboratory of Physical Chemistry, ETH Zürich, CH-8093 Zürich, Switzerland
}

\begin{abstract}
Mixed transition metal nickel oxide materials ( $\mathrm{M}-\mathrm{NiO} ; \mathrm{M}=\mathrm{Co}, \mathrm{Mn}, \mathrm{Fe}$ ) supported on silicone nanofilaments ( $\mathrm{SNFs}$ ) were synthesized via precipitation reaction with urea. All materials were evaluated for their OER activity in $0.1 \mathrm{M} \mathrm{KOH}$, of which the Fe-NiO/SNFs showed a notable improvement over $\mathrm{NiO} / \mathrm{SNF}$ and unsupported $\mathrm{NiO}$. The results presented herein demonstrate the extension of our previously reported synthesis for NiO/SNFs to yield SNF-supported mixed transition metal-oxide materials. The versatility and scalability of the synthesis are particularly interesting for the facile preparation of three-dimensional, binderless electrodes for alkaline water electrolysis applications.

(c) The Author(s) 2017. Published by ECS. This is an open access article distributed under the terms of the Creative Commons Attribution 4.0 License (CC BY, http://creativecommons.org/licenses/by/4.0/), which permits unrestricted reuse of the work in any medium, provided the original work is properly cited. [DOI: 10.1149/2.0201704jes] All rights reserved.

(cc) BY
\end{abstract}

Manuscript submitted December 15, 2016; revised manuscript received January 10, 2017. Published January 21, 2017.

The urgency for efficient large-scale energy storage and conversion systems continues to rise as the implementation of intermittent renewable energy sources, such as wind and solar energy harvesting plants, continues to become more prevalent. To meet this demand, the electrolytic splitting of water is expected to play a key role due to its ability to produce clean, carbon emission-free hydrogen fuel at high pressure..$^{1-3}$ Typically, the choice of highly active and stable electrocatalysts for use in acid-based polymer electrolyte water electrolysis (PEWE) is restricted to the noble metal oxides (i.e. $\mathrm{IrO}_{2} / \mathrm{RuO}_{2}$ ), the scarcity and high cost of which will largely impede widespread commercialization. In the past decade, however, alkaline water electrolysis has regained considerable attention as the development of alkaline anion exchange membranes with improved ionic conductivity and stability continues to show significant progress. ${ }^{4-7}$ Alkaline water electrolysis operates on the basis of the anodic oxygen evolution reaction (OER: $4 \mathrm{OH}^{-} \rightarrow 2 \mathrm{H}_{2} \mathrm{O}+\mathrm{O}_{2}+4 \mathrm{e}^{-}$) and concurrent cathodic hydrogen evolution reaction (HER: $4 \mathrm{H}_{2} \mathrm{O}+4 \mathrm{e}^{-} \rightarrow 2 \mathrm{H}_{2}$ $\left.+4 \mathrm{OH}^{-}\right)$. The high $\mathrm{pH}$ environment associated with alkaline water electrolysis greatly expands the repertoire of OER catalyst candidate materials due to the heightened stability and relatively high activity of transition metal oxides in basic media. To date, Ni-based oxides have perhaps been the most promising OER catalysts for alkaline water electrolysis in terms of cost, stability, and activity, especially those containing Fe. ${ }^{8-11}$

$\mathrm{Ni}$-based oxides have been widely explored as OER electrocatalysts for use in alkaline water electrolysis throughout the years and even commercial systems currently utilize Ni-coated steel electrodes. ${ }^{9}$ More recently, the mixed metal hydroxides containing both $\mathrm{Ni}$ and Fe represent some of the most widely investigated catalysts due to the low OER overpotentials encountered in alkaline electrolytes and also at near-neutral $\mathrm{pH}$ conditions. ${ }^{8,11-17}$ To date, however, most electrodes for alkaline electrolysis are prepared as thin films on a two dimensional (2D) substrate using methods such as electrodeposition, dip-coating, or spin-coating. As a result, many research efforts have been directed at developing three-dimensional (3D) electrode structures that offer much higher electrocatalytically active surface areas while maintaining high mechanical stability, high electrical conductivity, and sufficient porosity to allow for efficient gas and liquid transport. ${ }^{18-23}$

We have previously reported on the synthesis and extreme wetting properties of silicone nanofilaments (SNFs) ${ }^{24-26}$ More recently we have demonstrated their use as a $3 \mathrm{D}$ catalyst support for $\mathrm{NiO}$, which

\footnotetext{
$=$ These authors contributed equally to this work.

* Electrochemical Society Member.

${ }^{\text {zE} E-m a i l: ~ t h o m a s j u s t u s . s c h m i d t @ p s i . c h ; ~ s s e e g e r @ c h e m . u z h . c h ~}$
}

has been shown to offer several benefits over unsupported $\mathrm{NiO}^{27}$ for the OER in alkaline media. The chemical vapor deposition synthetic process for preparing SNFs allows for the growth of thin films on a variety of different surfaces, which could even be extended to the direct growth on ion exchange membranes. Furthermore, the process has been shown to be highly scalable, such that films can be grown on extended surface areas of several square meters. ${ }^{28}$ The extensive 3D micro and nanostructure of the filaments offers a solid support structure, which then negates the need for a binder. This is an added advantage given that it has been shown that polymer-based binders often diminish the enhancing effects of the nanostructure when constructing the final electrodes.

In this work we aim to extend our previous findings on $\mathrm{NiO} / \mathrm{SNF} .{ }^{27}$ Preparing $\mathrm{NiO}$ with the incorporation of alternative transition metal cations has been shown to lead to significant improvements in OER activity, especially in the case of Ni-Fe oxides. Here we show that our previously reported synthesis for NiO/SNFs can be extended to yield $\mathrm{M}-\mathrm{NiO} / \mathrm{SNFs}(\mathrm{M}=\mathrm{Co}, \mathrm{Mn}, \mathrm{Fe})$, which show an improved catalytic activity when compared to NiO/SNFs.

\section{Experimental Methods}

Materials Preparation.-Fluorine doped tin oxide (FTO) coated glass substrate (8 $\Omega \mathrm{m}^{-2}$, TCO30-8, Solaronix SA, Switzerland) were cut in pieces of $25 \mathrm{~mm} \times 25 \mathrm{~mm} \times 3 \mathrm{~mm}$. Trichloroethylsilane ( $\geq 97 \%$, Merck), nickel(II) nitrate hexahydrate ( $\geq 98.5 \%$, SigmaAldrich), cobalt(II) nitrate hexahydrate ( $\geq 98 \%$, Sigma-Aldrich), manganese(II) nitrate tetrahydrate ( $\geq 97 \%$, Sigma-Aldrich), iron(II) chloride tetrahydrate ( $\geq 99 \%$, Sigma-Aldrich) and urea ( $>99.5 \%$, Fluka) were used as received. Ultrapure water $(18.2 \mathrm{M} \Omega \mathrm{cm})$ was prepared by a Simplicity water purification system (Millipore, USA).

Silicone nanofilament coating on FTO glass substrate.-FTO glass substrates were ultrasonicated in a $10 \%(\mathrm{v} / \mathrm{v})$ aqueous solution of Deconex 11 Universal (Borer Chemie AG, Switzerland) for $15 \mathrm{~min}$ at $50^{\circ} \mathrm{C}$, rinsed with bidistilled water and dried under a stream of nitrogen. It should be noted that although FTO is used as a substrate for the scope of this study, other substrates (e.g., such as metal grids to allow for the direct implementation of the coated grid in an electrolyzer) would need to be used for technical applications. The cleaned FTO glass substrates were put upright in a desiccator (volume: $6.5 \mathrm{~L}$ ). The sealed desiccator was then flushed with humidified nitrogen for $1 \mathrm{~h}$ to obtain a relative humidity of $40 \%$ inside the desiccator. Afterwards, trichloroethylsilane $(500 \mu \mathrm{l}, 3.8 \mathrm{mmol})$ was injected through a septum and the gas phase reaction proceeded for $4 \mathrm{~h}$. Coated FTO glass substrates were rinsed with bidistilled water, dried under a stream of 
nitrogen and activated by oxygen plasma treatment (power $100 \mathrm{~W}, 5$ $\mathrm{min}$ ) in a low pressure plasma generator (Femto, Diener Electronic, Germany).

Preparation of $\mathrm{Co}, \mathrm{Mn}$ or $\mathrm{Fe}-\mathrm{NiO}$ covered silicone nanofilaments.-Activated silicone nanofilament coated FTO glass substrates were positioned upright in a custom made sample holder placed in a beaker (diameter: $5 \mathrm{~cm}$, volume: $150 \mathrm{~mL}$ ). Ultrapure water $(100 \mathrm{~mL})$ was added and the beaker was set in an ice bath. Under stirring, first urea $(1.02 \mathrm{~g}, 17.0 \mathrm{mmol})$ and then nickel nitrate hexahydrate $(3.71 \mathrm{~g}, 12.8 \mathrm{mmol})$ together with either cobalt nitrate hexahydrate $(0.41 \mathrm{~g}, 1.4 \mathrm{mmol})$, manganese nitrate tetrahydrate $(0.36 \mathrm{~g}, 1.4 \mathrm{mmol})$ or iron chloride tetrahydrate $(0.28 \mathrm{~g}, 1.4 \mathrm{mmol})$ were added in small portions. The reaction mixture was stirred in the ice bath for another $5 \mathrm{~min}$. Subsequently, the beaker was put in an oil bath at $80^{\circ} \mathrm{C}$ and stirred for $6 \mathrm{~h}$ to produce the $\mathrm{M}-\mathrm{Ni}(\mathrm{OH})_{2}$ samples $(\mathrm{M}=\mathrm{Co}, \mathrm{Mn}$, $\mathrm{Fe})$. The samples were removed from the reaction solution, rinsed with bidistilled water and left to dry at ambient conditions. Afterwards, the samples were calcinated in air by ramping the temperature to $400^{\circ} \mathrm{C}$ within $2 \mathrm{~h}$ and keeping $400^{\circ} \mathrm{C}$ for $5 \mathrm{~h}$ to yield the $\mathrm{M}-\mathrm{NiO}$ $(\mathrm{M}=\mathrm{Co}, \mathrm{Mn}, \mathrm{Fe})$.

Physical characterization.-Powder X-ray diffraction (PXRD) was performed on a STADI P diffractometer (STOE, Germany) in transmission mode (flat sample holders, Ge monochromator and Mo $K_{\alpha}$ radiation) equipped with a position sensitive detector. For PXRD analysis $\mathrm{Co}, \mathrm{Mn}$ or $\mathrm{Fe}-\mathrm{NiO}$ covered silicone nanofilaments were scratched off from FTO glass substrates.

Scanning electron microscopy (SEM) samples were mounted on aluminum stubs with conductive carbon tape and sputter coated with $15 \mathrm{~nm}$ platinum. The SEM images were recorded on a Zeiss Supra 50 VP (Zeiss, Germany) at $2 \mathrm{kV}$ using the inlens detector.

Transmission electron microscopy (TEM/STEM), selected area electron diffraction (SAED) and energy dispersive X-ray (EDX) analysis were performed on a Tecnai G2 Spirit (FEI, The Netherlands) at $120 \mathrm{kV}$. Samples for TEM/STEM analysis were prepared by ultrasonicating coated FTO glass substrate (approximately $1 \mathrm{~cm}^{2}$ cut in small pieces) in ethanol ( $1 \mathrm{~mL}$ ) for $1 \mathrm{~min}$. Subsequently, some drops of the dispersion were pipetted on formvar/carbon film coated aluminum grid and dried in air.

Attenuated total reflectance Fourier transform infrared (ATRFTIR) spectra were recorded on a VERTEX 70 spectrometer (Bruker, Switzerland) equipped with a MIRacle ATR device (Pike Technologies, Inc., USA) and a MCT detector cooled with liquid nitrogen. Prior to ATR-FTIR measurements metal oxide resp. hydroxide covered silicone nanofilaments were scraped from FTO glass substrates.

Elemental analyses were performed by Mikroanalytisches Labor Pascher (Remagen, Germany). Co, Mn or Fe-NiO covered silicone nanofilaments were removed from FTO glass substrates for the elemental analysis.

Electrochemical methods.-Electrochemical measurements were performed in a home-made polypropylene (PP) 3-electrode electrochemical cell using a BioLogic (VMP-300) potentiostat. Working electrodes were prepared by coating the $\mathrm{M}-\mathrm{NiO}$ silicone nanofilaments onto a square of fluorine doped tin oxide (FTO; $\mathrm{A}_{\text {geo }} \approx 6$ $\mathrm{cm}^{2}$ ). Electrical contact was made at the top of the electrode using a piece of Pt foil and an exposed electrode area of ca. $2.5-3.0 \mathrm{~cm}^{2}$ was submerged in the electrolyte. A reversible hydrogen electrode (RHE) served as the reference electrode and a piece of Au mesh served as the counter electrode. All potentials reported refer to the RHE scale. The electrolyte used for all experiments was $0.1 \mathrm{M} \mathrm{KOH}$ prepared from pellets (semiconductor grade, $99.99 \%$ trace metal basis, Sigma Aldrich), which was saturated with synthetic air prior to all measurements. Cyclic voltammograms were collected in the range of 0.6 to $1.8 \mathrm{~V}$ at a scan rate of $10 \mathrm{mV} \mathrm{s}^{-1}$ for 30 consecutive cycles. Subsequently, chronoamperometric measurements were performed in the range of 1.2 to $1.7 \mathrm{~V}$ while holding for 1 hour at each potential step. Cyclic voltammograms were then collected once again for 4 consec- utive cycles. All measurements were repeated at least three times to ensure reproducibility.

\section{Results and Discussion}

Physical characterization.-The thickness of the entangled, uncoated silicone nanofilament (SNF) layer grown on fluorine doped tin oxide (FTO) glass substrate was measured prior to the deposition of $\mathrm{M}-\mathrm{Ni}(\mathrm{OH})_{2}(\mathrm{M}=\mathrm{Co}, \mathrm{Mn}, \mathrm{Fe})$ using scanning electron microscopy (SEM, not shown) and ranged from $5 \mu \mathrm{m}$ to $8 \mu \mathrm{m}$. Individual filaments were approximately $20 \mathrm{~nm}-120 \mathrm{~nm}$ in diameter with a mean of $60 \pm 20 \mathrm{~nm}$. These observations are consistent with our previous reports on SNFs, and SEM images representative of the uncoated network can be found in Reference 27. After deposition of $\mathrm{M}-\mathrm{Ni}(\mathrm{OH})_{2}$ and subsequent annealing at $400^{\circ} \mathrm{C}$, SEM studies ( $c f$. Figures 1a1f) reveal the highly entangled, surface-bound network of SNFs that are coated along their longitudinal axis with a shell of M-NiO. The SEM analysis highlights the presence of interconnected petal-like nanosheets that give rise to the 3D flower-like morphology of the $\mathrm{NiO}$ nanostructures, which has been observed for $\alpha-\mathrm{Ni}(\mathrm{OH})_{2}{ }^{29-31}$ and Nibased layered double hydroxide (LDH) materials. ${ }^{32}$ The formation of this distinct morphology was followed over the course of the reaction (i.e. placing the SNF coated FTO in a solution of the metal precursors and urea for $6 \mathrm{~h}$ at $80^{\circ} \mathrm{C}$ ). Figure $\mathrm{S} 1 \mathrm{a}-\mathrm{c}$ shows that the filaments collapse and only an initial formation of the $\mathrm{M}-\mathrm{Ni}(\mathrm{OH})_{2}$ layer is observed after 2 hours of reaction time. On the contrary, after 6 hours of reaction time the shell is completely developed and fully surrounds the SNFs, exhibiting the characteristic morphology of interconnected nanosheets (Figure S1d-f). Furthermore, a comparison of the materials before and after calcination shows no significant detrimental effects on the structure caused by the calcination step ( $c f$. Figures S1d-f and Figures 1a-1f). As a result, the SNF network and shell morphology are well preserved during the conversion of $\mathrm{M}-\mathrm{Ni}(\mathrm{OH})_{2}$ to the target $\mathrm{M}-\mathrm{NiO}$ phase. Complimentary information regarding size and morphology of the M-NiO shell was obtained through transmission electron microscopy (TEM/STEM) analysis. The TEM/STEM observations further highlight the intricate intersecting nature of the $\mathrm{NiO}$ nanosheets and corroborate that they surround the intact silicone nanofilaments (Figures 1g-11). The thickness of the Co- and $\mathrm{Mn}-\mathrm{NiO}$ nanosheets falls in the range of $22-50 \mathrm{~nm}$, which is similar to the $\mathrm{NiO}$ nanosheets reported previously for NiO/SNFs. ${ }^{27}$ The Fe-NiO nanosheets are slightly larger and thinner with thicknesses ranging from approximately $21-38 \mathrm{~nm}$ and a morphology closely resembling that reported for Ni-Fe layered double hydroxide (LDH) materials. ${ }^{32}$ Furthermore, the TEM/STEM analysis revealed mesoporosity within the M-NiO nanosheets ( $c f$. Figure 1g-11), which is an important feature to facilitate the mass transport of the electrolyte. ${ }^{33}$ These porous features are formed during the calcination step and have been attributed to the evaporation of intercalated water. ${ }^{34}$

Figure 2 shows the powder X-ray (PXRD) diffractograms for the $\mathrm{M}-\mathrm{NiO} / \mathrm{SNF}$ after calcination. The observed reflections were matched to the cubic NiO crystalline structure (JCPDS 00-047-1049), which confirms the conversion of the calcined deposits to the targeted nickel oxide phase. The sharp diffraction peaks clearly demonstrate the high level of crystallinity obtained for the Co- and Mn-NiO/SNFs samples. The polycrystalline nature of the $\mathrm{M}-\mathrm{NiO}$ was further supported by selected area electron diffraction (SAED) ring patterns (Figures 2b-2d). The diffraction rings match the (111), (200), (220), (311) and (222) planes, which is in line with the PXRD results. In contrast, the XRD pattern of Fe-NiO shows a lower degree of crystallinity as evidenced by the significantly lower diffraction peak intensity. This is in agreement with the SAED pattern which also exhibits more diffuse diffraction rings. It should be noted that the positions of the PXRD peaks corresponding to the $\mathrm{NiO}$ phase are close to those of $\mathrm{NiFe}_{2} \mathrm{O}_{4}$, indicating that the $\mathrm{Fe}-\mathrm{NiO}$ might also contain $\mathrm{NiFe}_{2} \mathrm{O}_{4}$, which further suggests the formation of an additional Ni-Fe LDH phase.

Although the ideal metal dopant concentration for mixed Ni$\mathrm{M}$ oxides is quite controversial in the literature, some studies have 

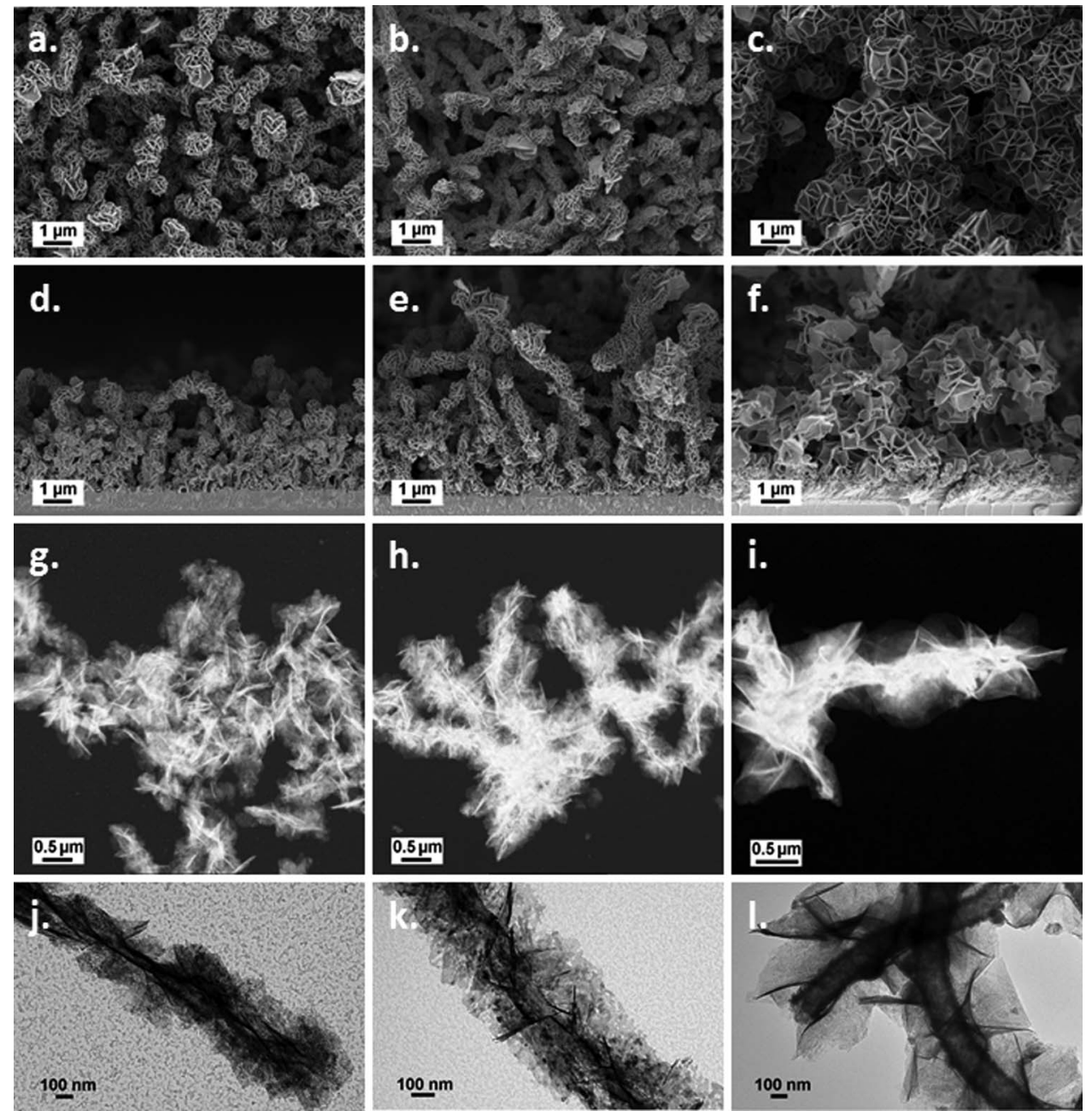

Figure 1. Electron microscopic characterization of the materials. Top-view and cross-sectional SEM images: (a,d) Co-NiO/SNFs, (b,e) Mn-NiO/SNFs, and (c,f) Fe-NiO/SNFs. STEM images: (g) Co-NiO/SNFs, (h) Mn-NiO /SNFs, and (i) Fe-NiO/SNFs. TEM images: (j) Co-NiO/SNFs, (k) Mn-NiO/SNFs, and (l) $\mathrm{Fe}-\mathrm{NiO} / \mathrm{SNF}$.
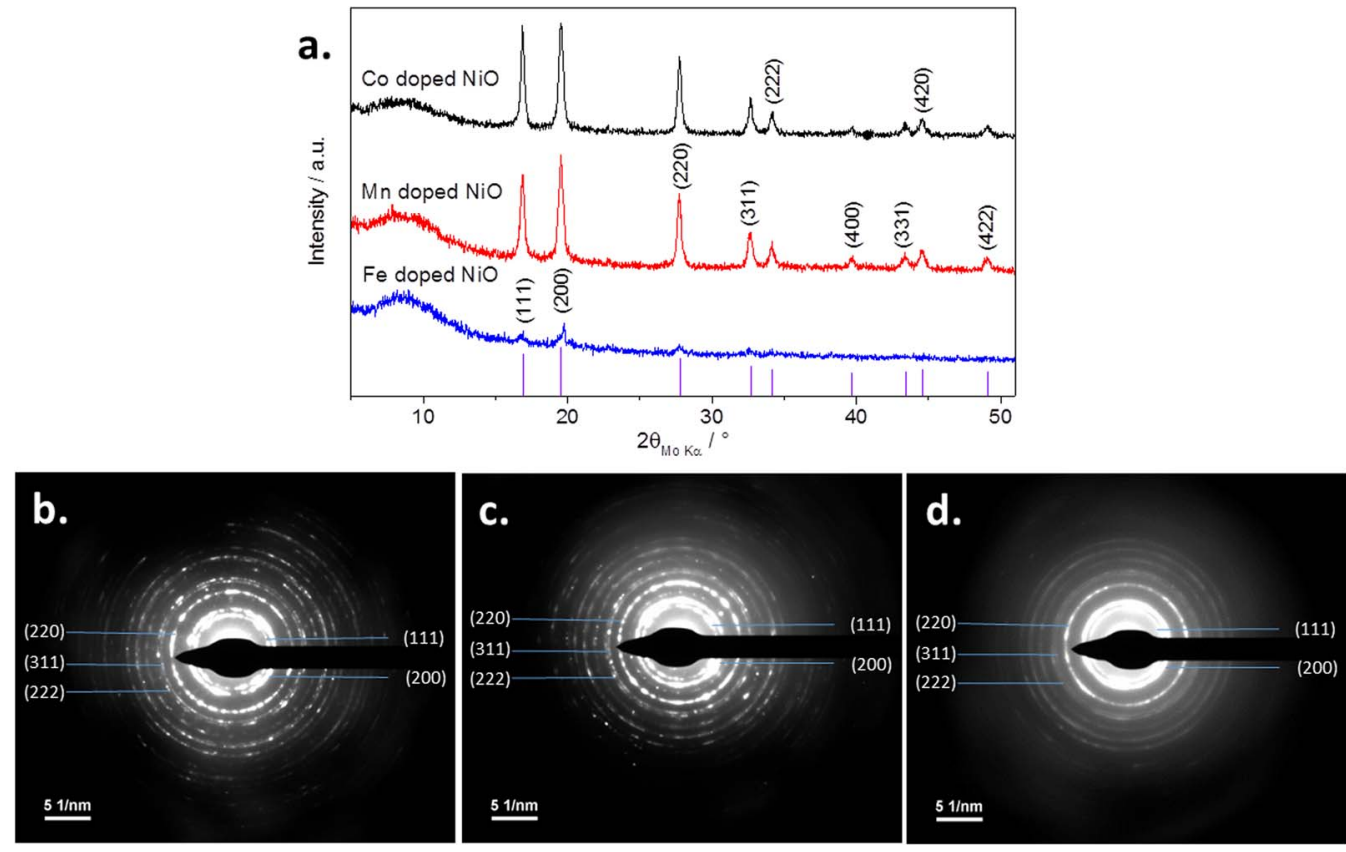

Figure 2. Powder X-ray diffractograms for the prepared M-NiO/SNFs (a), and the SAED ring patterns of Co-NiO (b), $\mathrm{Mn}-\mathrm{NiO}$ (c), and Fe-NiO (d) indexed to the lattice planes of cubic NiO (JCPDS card 00-047-1049). 
revealed that $10 \mathrm{~mol} \% \mathrm{Fe}$ dopant content ${ }^{7,11,35,36}$ provides the best improvement in the OER activity for Fe-Ni oxides. Therefore this was chosen as the target dopant concentration and was used for the preparation of all $\mathrm{M}-\mathrm{NiO}$ materials $(\mathrm{M}=\mathrm{Co}, \mathrm{Mn}$ and $\mathrm{Fe})$ to maintain an identical synthesis route. The incorporation of the alternative transition metals $(\mathrm{Co}, \mathrm{Mn}, \mathrm{Fe}$ ) into the samples is confirmed in the corresponding energy dispersive X-ray (EDX) spectra ( $c f$. Figure S2). In addition to the alternative transition metals and the elements of $\mathrm{NiO}$ $(\mathrm{Ni}, \mathrm{O})$, the elements of the silicone nanofilaments $(\mathrm{Si}, \mathrm{O}, \mathrm{C})$ were also detected. The $\mathrm{Al}$ and $\mathrm{C}$ signals that arise can be attributed to the formvar coated TEM-grid. A comparison of the peak ratios shows that the concentration of the alternative transition metal is much higher in $\mathrm{Fe}-\mathrm{NiO} / \mathrm{SNF}$ s than in the Mn-NiO/SNFs and $\mathrm{Co}-\mathrm{NiO} / \mathrm{SNF}$ s samples. This is surprising since the same molar ratios were used for preparation of all the samples. Additional results obtained from elemental analysis confirm this observation and show that the samples contained $7.5 \mathrm{~mol} \% \mathrm{Co}, 2.1 \mathrm{~mol} \% \mathrm{Mn}$, and $51.2 \mathrm{~mol} \% \mathrm{Fe}$, respectively ( $c f$. Table S1). Analysis of the SEM images of the $\mathrm{Fe}-\mathrm{Ni}(\mathrm{OH})_{2} / \mathrm{SNFs}$ in Figure $\mathrm{S} 1$ suggests a two-stage process for the formation of the inorganic shell. First, a deposition of particles on the SNFs occurs; then, the nanosheets are formed. The TEM image shown in Figure S3a confirmed the presence of two distinct structures. In addition, the EDX point-spectra ( $c f$. Figure S3b) reveal a higher iron-to-nickel ratio in the particles than in the nanosheets. It should also be noted that some red precipitate was observed on the bottom of the beaker after the deposition of $\mathrm{Fe}-\mathrm{Ni}(\mathrm{OH})_{2}$ on the SNF support structure. This hierarchical structure made up of iron-rich particles and low iron containing nanosheets may account for the relatively high amounts of Fe detected in the as-deposited sample via EDX and elemental analysis.

The ATR-IR spectra for the M-NiO/SNFs samples before and after calcination are presented in Figure S4. The initial formation of $\mathrm{Ni}(\mathrm{OH})_{2}$ is confirmed by the characteristic bands for the $\mathrm{Ni}-\mathrm{OH}$ lattice modes and $\mathrm{O}-\mathrm{H}$ stretching modes in $\alpha-\mathrm{Ni}(\mathrm{OH})_{2}$, which are clearly observed prior to calcination at $600-800 \mathrm{~cm}^{-1}$ and $3620 \mathrm{~cm}^{-1}$, respectively. ${ }^{37-39}$ The band at $1620 \mathrm{~cm}^{-1}$ has been ascribed to the hydroxyl deformation mode (O-H bending) of water molecules adsorbed to the surface or within the layers of the material. ${ }^{32,38}$ Additionally, the presence of incorporated anions such as carbonate $\left(1600 \mathrm{~cm}^{-1}\right.$ and $\left.1400 \mathrm{~cm}^{-1}\right)$ and cyanate $\left(2250 \mathrm{~cm}^{-1}\right)$ can be identified. ${ }^{37}$ The narrow bands associated with these species arise from the thermal decomposition of urea, which is used to precipitate $\mathrm{Ni}(\mathrm{OH})_{2}$ during the synthesis. However, the vibrational bands associated with cyanate and carbonate are no longer visible after calcination at $400^{\circ} \mathrm{C}$, confirming that they are successfully removed from the final product. Similarly, the vibrational modes of nitrate, which is the counter ion of nickel in the starting material, can be observed before calcination at ca. $1280-1340 \mathrm{~cm}^{-1} .38$ The absence of $\mathrm{OH}$ vibrational modes after calcination further confirm the conversion of the as-deposited $\mathrm{M}-\mathrm{Ni}(\mathrm{OH})_{2}$ to the targeted $\mathrm{M}-\mathrm{NiO}$ phase during the calcination step. The additional broad band at $1200-900 \mathrm{~cm}^{-1}$ in the $\mathrm{Fe}-\mathrm{NiO}$ spectra can be attributed to the characteristic modes of the Si-O-Si chain of the underlying silicone nanofilaments.

Electrochemical characterization.-We have previously demonstrated that $\mathrm{NiO} / \mathrm{SNF}$ offer an improvement over unsupported $\mathrm{NiO}$ in terms of OER activity. ${ }^{27}$ In order to evaluate the possible advantages of including alternative transition metals in the NiO/SNFs materials, we again evaluate the OER activity in alkaline media. Figure 3 presents the electrochemical behavior of the M-NiO/SNFs $(\mathrm{M}=\mathrm{Co}$, $\mathrm{Mn}, \mathrm{Fe}$ ) in $0.1 \mathrm{M} \mathrm{KOH}$. It should be noted that the current density has been normalized by the total metal oxide loading on the electrode in all cases. The cyclic voltammograms shown in Figures $3 a-3 d$ depict the development of the M-NiO/SNFs materials over the course of potential cycling between 0.6 and $1.8 \mathrm{~V}$ vs. RHE. The presence of the anodic and cathodic $\mathrm{Ni}^{2+} / \mathrm{Ni}^{3+}$ redox peaks are clearly observed in the case of the Co- and Mn-NiO/SNFs materials (Figures 3a and $3 b)$. While the cathodic and anodic peak positions for NiO/SNFs were reported to be 1.34 and $1.48 \mathrm{~V}$ vs. RHE $^{27}$ (Figure $3 \mathrm{~d}$ ), the initial peak positions (i.e. $2^{\text {nd }} \mathrm{CV}$ cycle) of the Co-NiO/SNFs $(1.31 / 1.42 \mathrm{~V})$ are shifted to slightly lower potentials (Figure $3 \mathrm{a}$ ). The slight shift to lower potentials indicates that the trivalent $\mathrm{Co}$ facilitates the oxidation of $\mathrm{Ni}^{2+}$ to $\mathrm{Ni}^{3+},{ }^{13,40}$ although the shift is not nearly as prominent as previous reports have indicated. This, however, can be rationalized and supported by the EDX analysis (See Figure S2), which shows that only a small fraction of $\mathrm{Co}$ is present. In Figure $3 \mathrm{~b}$ we observe that the $\mathrm{Mn}-\mathrm{NiO} / \mathrm{SNF}$ also exhibit a shift in the $\mathrm{Ni}^{2+/ 3+}$ redox peaks $(1.27 / 1.47 \mathrm{~V})$, but in this case the shift of the anodic and cathodic peaks to higher and lower potentials, respectively, results in a wider peak separation. Given that the cathodic peak undergoes a more substantial shift than the anodic peak, this may indicate that the incorporation of tetravalent $\mathrm{Mn}$ species help to stabilize the $\mathrm{Ni}^{3+}$ state. In contrast to both the Co- and Mn-NiO/SNFs, however, the Ni redox features of $\mathrm{Fe}-\mathrm{NiO} / \mathrm{SNF}$ are significantly muted to the point where they are essentially nonexistent (Figure 3c). This may be indicative of an Fe-rich surface, which is in line with the relatively high Fe content as detected by the elemental and EDX analyses. However, it is also very likely that $\mathrm{Fe}$ helps to stabilize the $\mathrm{Ni}^{2+}$ oxidation state such that the $\mathrm{Ni}^{2+/ 3+}$ redox couple is shifted to higher potentials. This effect has been recognized by several authors recently in $\mathrm{Ni}-\mathrm{Fe}$ hydroxide materials. ${ }^{12,13,16,23}$ Furthermore, our observations for both the Ni-Fe and Ni-Co based systems agree well with the charge transfer effects that were recently reported by Bates et al. ${ }^{13}$

The final $\left(31^{\mathrm{st}}\right)$ cycles of each electrode are compared in Figure 3e. From Figure $3 \mathrm{e}$ we observe that the magnitude of the $\mathrm{Ni}^{2+/ 3+}$ redox peaks for the Co-NiO/SNFs and Mn-NiO/SNFs increases as the electrode is cycled. This is agreement with previous studies indicating the formation of a hydrous $\mathrm{Ni}(\mathrm{OH})_{2} / \mathrm{NiOOH}$ layer upon electrode cycling. Although it is well known that $\mathrm{NiO}$ undergoes a spontaneous conversion to $\mathrm{NiOOH}$ once immersed in basic media, the increasing magnitude of the Ni redox features clearly shows that the hydrous layer and therefore the electrochemically active surface area continues to grow with cycling. Accompanying the increase in peak magnitude, however, is a simultaneous increase in the anodic/cathodic peak separation. This is particularly noticeable on the Mn-NiO/SNFs, which indicates that the reversibility diminishes with cycling. This finding can be attributed to a combination of two separate effects. On the one hand, the growth of the hydrous surface layer contributes to the increased surface electrochemically active surface area and therefore the amplitude of the characteristic $\mathrm{Ni}^{2+/ 3+}$ redox features. On the other hand, the wider peak separation is observed due to an increase in the uncompensated resistance of the oxide film over the course of potential cycling as a result of limited diffusion within the extended growth of the hydroxide layers of the material.

The corresponding Tafel plots are shown in Figure $3 \mathrm{f}$ and the calculated parameters and uncertainties resulting from the averaging of 3 separate polarization measurements are presented in Table I. The Co- and Mn-Ni/SNFs materials show Tafel slopes of $39 \pm 5$ and 43 $\pm 4 \mathrm{mV} \mathrm{dec}{ }^{-1}$, respectively, which are comparable to the Tafel slope of $50 \pm 2 \mathrm{mV} \mathrm{dec}^{-1}$ that was previously reported for $\mathrm{NiO} / \mathrm{SNFs}^{27}$ and indicates that the OER proceeds through a similar mechanism. In contrast, the $\mathrm{Fe}-\mathrm{NiO} / \mathrm{SNF}$ s sample shows a significantly lower

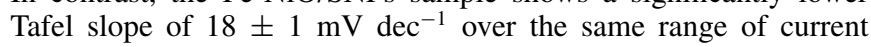
densities. Similar values have been reported previously for $\mathrm{Ni}-\mathrm{Fe}$ hydroxide materials, ${ }^{35,41}$ which may reflect an overlap of both the OER and the $\mathrm{Ni}^{2+} / \mathrm{Ni}^{3+}$ redox couple operating simultaneously. It can be observed, however, that the Tafel slope shifts to a value comparable to that of the other M-NiO/SNFs samples (ca. $42 \mathrm{mV} \mathrm{dec}^{-1}$ ) at higher current densities and therefore a value more representative of the OER kinetics. Table I also presents the mass-based OER activities ( $E$ at $J=10 \mathrm{~A} \mathrm{~g} \mathrm{gx}_{\mathrm{ox}}{ }^{-1}$ ) derived from the steady-state polarization curves for each sample. The calculated activity of the Co- and Mn-NiO/SNFs samples both show a comparable activity to that of the pure NiO/SNFs. This is in agreement with literature reports of mixed metal hydroxide catalysts of similar composition (i.e. M-Ni concentration) ${ }^{17}$ and is rather reasonable given the relatively low dopant metal content in these samples. In general, the polarization measurements show the 

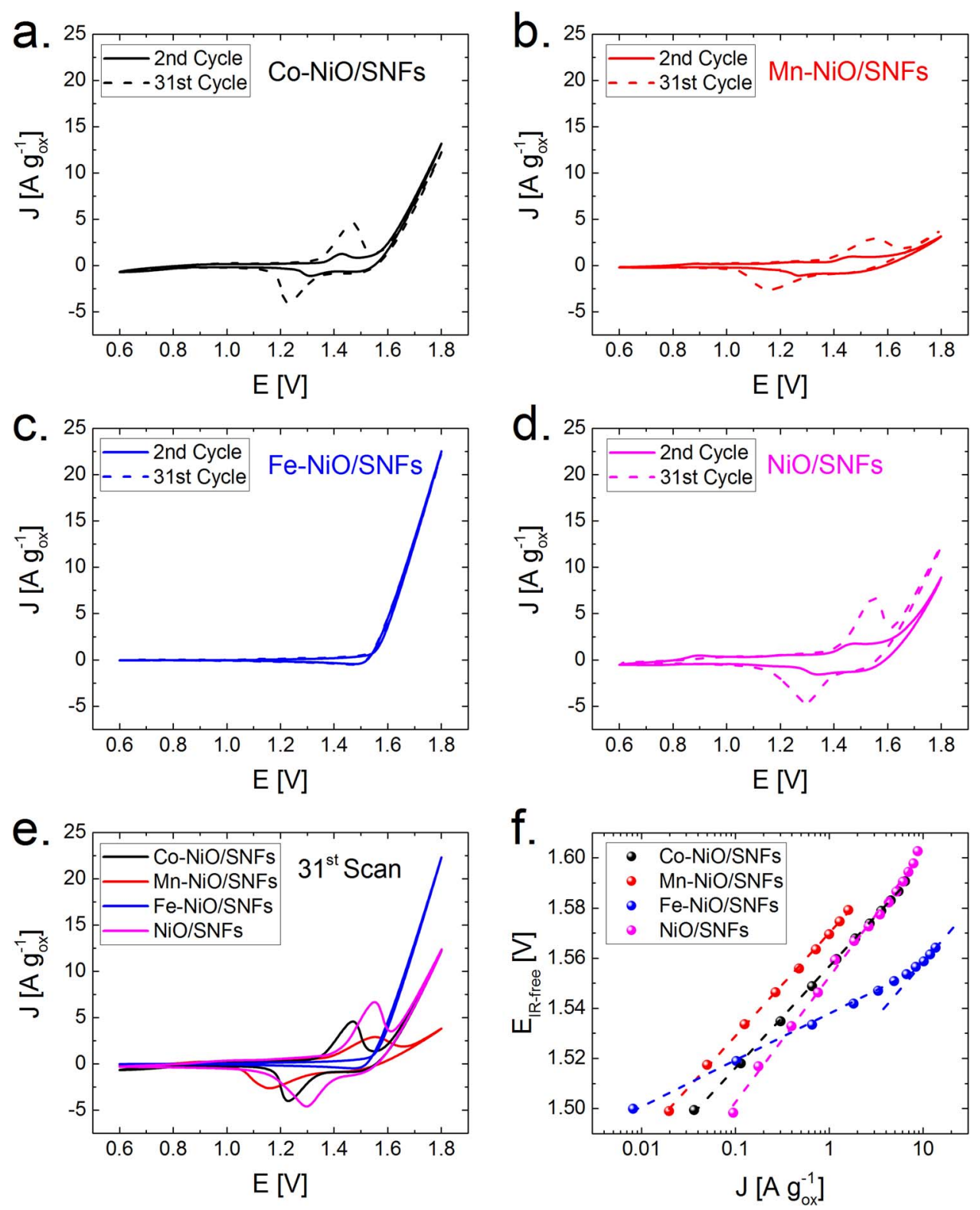

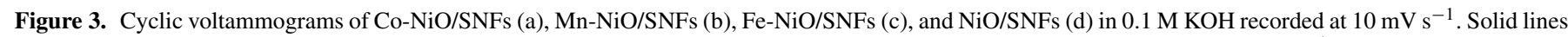
represent the 2 nd cycle and dashed lines represent the final (31st) cycle prior to recording the polarization curve; comparison of the $31^{\text {st }}$ cycle for all $\mathrm{M}-\mathrm{Ni} / \mathrm{SNF}$ materials (e); and the Tafel plots of M-NiO/SNFs in $0.1 \mathrm{M} \mathrm{KOH} \mathrm{(f).} \mathrm{Steady} \mathrm{state} \mathrm{current} \mathrm{values} \mathrm{were} \mathrm{measured} \mathrm{after} \mathrm{holding} \mathrm{at} \mathrm{the} \mathrm{applied} \mathrm{potential} \mathrm{for} 1$ hour.

same general trend as reported in the literature ${ }^{10}$ with the highest activity and lowest onset potential following the order $\mathrm{Fe}>\mathrm{Co}>$ Mn.

A comparison to the previously reported $\mathrm{NiO} / \mathrm{SNF}$ indicates that while the incorporation of low concentrations of Co or Mn offers no obvious benefit, the incorporation of $\mathrm{Fe}$ into the $\mathrm{NiO} / \mathrm{SNF}$ results in a notable improvement in the electrochemical OER activity. Given that

Table I. Tafel slope and electrochemical activity parameters for the M-NiO/SNF electrodes.

\begin{tabular}{lll} 
Electrode & Tafel Slope, $\mathrm{mV} \mathrm{dec}^{-1}$ & $E$ @ $J=10 \mathrm{~A} \mathrm{gox}^{-1}, \mathrm{~V}$ \\
\hline $\mathrm{Co}-\mathrm{NiO} / \mathrm{SNFs}$ & $39 \pm 5$ & $1.60 \pm 0.014$ \\
$\mathrm{Mn}-\mathrm{NiO} / \mathrm{SNFs}$ & $43 \pm 4$ & $1.61 \pm 0.015$ \\
$\mathrm{Fe}-\mathrm{NiO} / \mathrm{SNFs}$ & $18 \pm 1$ & $1.54 \pm 0.014$ \\
$\mathrm{NiO} / \mathrm{SNFs}^{27}$ & $50 \pm 2$ & $1.61 \pm 0.012$
\end{tabular}

$\mathrm{NiO} / \mathrm{SNF}$ s was already shown to provide a significant improvement as compared to unsupported $\mathrm{NiO}$, these results demonstrate the advantages of using $\mathrm{M}-\mathrm{NiO} / \mathrm{SNF}$ over unsupported or pure $\mathrm{NiO}$ materials.

\section{Conclusions}

Silicone nanofilament-supported $\mathrm{M}-\mathrm{Ni}(\mathrm{M}=\mathrm{Mn}, \mathrm{Co}, \mathrm{Fe})$ oxide materials were successfully prepared via an aqueous precipitation reaction with urea and subsequent calcincation. The prepared materials were shown to conform to the cubic $\mathrm{NiO}$ crystalline structure, except for the Ni-Fe material which showed additional features characteristic of $\mathrm{NiFe}_{2} \mathrm{O}_{4}$. All materials were shown to be active for the OER. A direct comparison to the previously reported $\mathrm{NiO} / \mathrm{SNF}$ indicates that while the incorporation of low concentrations of Co or Mn offers no immediate benefit, the incorporation of $\mathrm{Fe}$ into the NiO/SNFs results in a notable improvement in the electrochemical OER activity. Considering that NiO/SNFs have already been shown to significantly enhance the OER activity versus unsupported $\mathrm{NiO}$, the successful 
preparation of SNF-supported Ni-Fe oxide further demonstrates the potential of SNFs to offer a suitable support structure for OER electrocatalysts with improved activity. Further development and optimization of the SNF-supported mixed metal oxides could lead to improved binderless electrodes suitable to alkaline water electrolysis applications. The work presented herein serves as an efficient initial screening tool for the M-NiO/SNFs electrocatalysts. Ongoing research efforts are currently focused on the deposition of the M-NiO/SNFs catalysts on industrially-relevant substrate materials to effectively demonstrate that the advantages reported can be translated into working electrodes in actual devices.

\section{Acknowledgments}

We thank Karla Lienau for performing XRD analysis and Patrizia Huggenberger for labaratory work support. The center of microscopy and image analysis of the University of Zurich is gratefully acknowledged for providing their facilities. CTI and the Swiss Competence Center for Energy Research Heat and Electricity Storage is greatly acknowledged by DFA; EF; and TJS.

\section{References}

1. L. Bertuccioli, A. Chan, D. Hart, F. Lehner, B. Madden, and E. Standen, Development of Water Electrolysis in the European Union, in, p. 83, Fuel Cells and Hydrogen Joint Undertaking (2014).

2. Quadrennial Technology Review 2015, in, U. S. D. o. Energy Editor, p. 489, U.S Department of Energy (2015).

3. J. D. Holladay, J. Hu, D. L. King, and Y. Wang, Catal. Today, 139, 244 (2009).

4. M. A. Hickner, A. M. Herring, and E. B. Coughlin, J. Polym. Sci., Part B: Polym. Phys., 51, 1727 (2013).

5. Y. Leng, G. Chen, A. J. Mendoza, T. B. Tighe, M. A. Hickner, and C.-Y. Wang, J. Am. Chem. Soc., 134, 9054 (2012).

6. J. Cheng, G. He, and F. Zhang, Int. J. Hydrogen Energy, 40, 7348 (2015).

7. D. Pletcher and X. Li, Int. J. Hydrogen Energy, 36, 15089 (2011).

8. F. Dionigi and P. Strasser, Advanced Energy Materials, 1600621 (2016).

9. K. Zeng and D. Zhang, Prog. Energy Combust. Sci, 36, 307 (2010).

10. E. Fabbri, A. Habereder, K. Waltar, R. Kotz, and T. J. Schmidt, Catal. Sci. Technol. 4, 3800 (2014).

11. X. Li, F. C. Walsh, and D. Pletcher, PCCP, 13, 1162 (2011).

12. M. Görlin, P. Chernev, J. Ferreira de Araújo, T. Reier, S. Dresp, B. Paul, R. Krähnert, H. Dau, and P. Strasser, J. Am. Chem. Soc., 138, 5603 (2016).

13. M. K. Bates, Q. Jia, H. Doan, W. Liang, and S. Mukerjee, ACS Catal., 6, 155 (2016)
14. Y.-F. Li and A. Selloni, ACS Catal., 4, 1148 (2014).

15. D. Friebel, M. W. Louie, M. Bajdich, K. E. Sanwald, Y. Cai, A. M. Wise, M.-J. Cheng, D. Sokaras, T.-C. Weng, R. Alonso-Mori, R. C. Davis, J. R. Bargar, J. K. Nørskov, A. Nilsson, and A. T. Bell, J. Am. Chem. Soc., 137, 1305 (2015).

16. L. Trotochaud, S. L. Young, J. K. Ranney, and S. W. Boettcher, J. Am. Chem. Soc., 136, 6744 (2014).

17. M. S. Burke, L. J. Enman, A. S. Batchellor, S. Zou, and S. W. Boettcher, Chem. Mater, 27, 7549 (2015).

18. J. Wang, H.-x. Zhong, Y.-l. Qin, and X.-b. Zhang, Angew. Chem. Int. Ed., 52, 5248 (2013).

19. Z.-S. Wu, S. Yang, Y. Sun, K. Parvez, X. Feng, and K. Müllen, J. Am. Chem. Soc., 134, 9082 (2012).

20. H.-C. Chien, W.-Y. Cheng, Y.-H. Wang, T.-Y. Wei, and S.-Y. Lu, J. Mater. Chem., 21, 18180 (2011).

21. C. Tang, N. Cheng, Z. Pu, W. Xing, and X. Sun, Angew. Chem. Int. Ed., 54, 9351 (2015).

22. S. Chen, J. Duan, J. Ran, M. Jaroniec, and S. Z. Qiao, Energy \& Environmental Science, 6, 3693 (2013).

23. Y. Qiu, L. Xin, and W. Li, Langmuir, 30, 7893 (2014).

24. J. Zimmermann, F. A. Reifler, G. Fortunato, L.-C. Gerhardt, and S. Seeger, $A d v$. Funct. Mater., 18, 3662 (2008).

25. J. Zhang and S. Seeger, Angew. Chem. Int. Ed., 50, 6652 (2011).

26. G. R. Meseck, A. Käch, and S. Seeger, J. Phys. Chem. C, 118, 24967 (2014).

27. G. R. Meseck, E. Fabbri, T. J. Schmidt, and S. Seeger, Advanced Materials Interfaces, 2, n/a (2015).

28. G. R. J. Artus and S. Seeger, Industrial \& Engineering Chemistry Research, 51, 2631 (2012).

29. L. Xu, Y.-S. Ding, C.-H. Chen, L. Zhao, C. Rimkus, R. Joesten, and S. L. Suib, Chem. Mater, 20, 308 (2008).

30. Y. Ren and L. Gao, J. Am. Ceram. Soc., 93, 3560 (2010).

31. A. Fihri, R. Sougrat, R. B. Rakhi, R. Rahal, D. Cha, M. N. Hedhili, M. Bouhrara, H. N. Alshareef, and V. Polshettiwar, ChemSusChem, 5, 1241 (2012).

32. X. Ting, T. Yiwen, J. Zhiyong, L. Dawei, H. Xiaoyan, L. Bihui, and L. Lijuan, Nanotechnology, 20, 475603 (2009).

33. C. Guan, J. Liu, C. Cheng, H. Li, X. Li, W. Zhou, H. Zhang, and H. J. Fan, Energy \& Environmental Science, 4, 4496 (2011).

34. S.-I. Kim, J.-S. Lee, H.-J. Ahn, H.-K. Song, and J.-H. Jang, ACS Applied Materials \& Interfaces, 5, 1596 (2013).

35. D. A. Corrigan, J. Electrochem. Soc., 134, 377 (1987).

36. J. Landon, E. Demeter, N. İnoğlu, C. Keturakis, I. E. Wachs, R. Vasić, A. I. Frenkel, and J. R. Kitchin, ACS Catal., 2, 1793 (2012).

37. G. J. d. A. A. Soler-Illia, M. Jobbágy, A. E. Regazzoni, and M. A. Blesa, Chem. Mater. 11, 3140 (1999).

38. D. S. Hall, D. J. Lockwood, S. Poirier, C. Bock, and B. R. MacDougall, The Journal of Physical Chemistry A, 116, 6771 (2012).

39. F. Portemer, A. Delahaye-Vidal, and M. Figlarz, J. Electrochem. Soc., 139, 671 (1992).

40. D. A. Corrigan and R. M. Bendert, J. Electrochem. Soc., 136, 723 (1989).

41. M. D. Merrill and R. C. Dougherty, J. Phys. Chem. C, 112, 3655 (2008). 